International Journal of

Environmental Research and

Public Health

ISSN 1660-4601

www.mdpi.com/journal/ijerph

Comment

\title{
Comments on Varela-Mato, V.; Cancela, J.M.; Ayan, C.; Martín, V.; Molina, A. Lifestyle and Health among Spanish University Students: Differences by Gender and Academic Discipline. Int. J. Environ. Res. Public Health 2012, 9, 2728-2741
}

\author{
Juan Jose Crespo-Salgado ${ }^{1, *}$ and Alicia Blanco-Moure ${ }^{2}$ \\ 1 Sports Medicine Specialist, University of Vigo, Pontevedra 36310, Spain \\ 2 Internal Medicine, Fatima Hospital of Vigo, Pontevedra 36206, Spain; \\ E-Mail: alicia.blanco.moure@sergas.es \\ * Author to whom correspondence should be addressed; E-Mail: crespo_salgado@uvigo.es; \\ Tel.: +34-986-81-4060.
}

Received: 14 June 2013 / Accepted: 29 July 2013 / Published: 13 August 2013

In regard to the article entitled "Lifestyle and health among Spanish university students: differences by gender and academic discipline" by Varela-Mato et al. [1] which analyzes the lifestyles of a group of students from the University of Vigo (Galicia, Spain), we would like to draw your attention to a series of disagreements with certain statements that are made therein:

1. The authors [1] transfer their results to the Spanish university with a transversal descriptive study without selection of the participants and that includes $27 \%$ of the students in one of the three campuses and does not exceed 5\% of total Students at the University of Vigo, and in which nothing is known of the subjects who did not respond to the questionnaires (see "The STROBE Statement") [2].

2. The authors use the short version of the questionnaire International Physical Activity Questionnaire (IPAQ [3]) and defined as sufficiently active to those who perform an energy expenditure greater than or equal to 1,500 Met-min/week. IPAQ itself [3] and related agencies such as the U.S. Department of Health and Human Services (USDHHS [4]), the UK National Institute of Health (NICE [5]), and the World Health Organization (WHO [6]), indicate that it is from an energy expenditure of $500 \mathrm{Met}-\mathrm{min} /$ week when defining a person as sufficiently active (equivalent to performing $150 \mathrm{~min} /$ week of moderate physical activity or $75 \mathrm{~min} /$ week vigorous physical activity).

3. With respect to the claim that the Varela-Mato et al. research was approved by the Ethics Committee of the University of Vigo, this cannot be because in that there is no such University 
Research Ethics Committee at that institution and there is only one ethics committee for the welfare of laboratory animals (SIUV [7]).

Given the circumstances, we disagree with some of the authors' conclusions and recommend their reconsideration.

\section{References}

1. Varela-Mato, V.; Cancela, J,M.; Ayan, C.; Martín, V.; Molina, A. Lifestyle and health among Spanish university students: Differences by gender and academic discipline. Int. J. Environ. Res. Public Health 2012, 9, 2728-2741.

2. Vandenbroucke, J.P.; von Elm, E.; Altman, D.G.; Gøtzsche, P.C.; Mulrow, C.D.; Pocock, S.J.; Poole, C.; Schlesselman, J.J.; Egger, M.; STROBE initiative. Strengthening the Reporting of Observational Studies in Epidemiology (STROBE): Explanation and elaboration. PLoS Med. 2007, doi:10.1371/journal.pmed.0040297.

3. IPAQ Research Committee. Guidelines for the Data Processing and Analysis of the International Physical Activity Questionnaire; 2005. Available online: http://www.ipaq.ki.se/scoring.pdf (accessed on 10 January 2013).

4. U.S. Department of Health and Human Services. Physical Activity Guidelines for Americans: Recommendation Statement; 2008. Available online: http://www.health.gov/paguidelines/ (accessed on 29 September 2012).

5. NICE. Modelling the Cost-Effectiveness of Physical Activity Interventions; National Institute for Health and Clinical Excellence: London, UK, 2006. Available online: http://www.nice.org.uk/ nicemedia/pdf/ FourmethodsEconomic Modelling Report.pdf (accessed on 25 September 2012).

6. WHO/OMS. Global Recommendations on Physical Activity for Health; World Health Organization: Geneve, Switzerland, 2010.

7. Servicio de Investigación de la Universidad de Vigo. Available online: https://www. uvigo.es/uvigo_gl/investigacion/comision/ (accessed on 10 January 2013).

(C) 2013 by the authors; licensee MDPI, Basel, Switzerland. This article is an open access article distributed under the terms and conditions of the Creative Commons Attribution license (http://creativecommons.org/licenses/by/3.0/). 